\title{
Research on the Innovation of Business Model in Sharing Economy Ke LIU ${ }^{1, a,{ }^{*}}$, Meng-Han CHEN ${ }^{2, b}$
}

School of Economics and Management Zhengzhou University of Light Industry, Zhengzhou, 450002, China

aliuke_liu@163.com, b114738673@qq.com

*Ke LIU

Keywords: Sharing economy, Business model, Innovation

\begin{abstract}
Sharing economy, created in the context of "Internet +", is a new business model in which individuals, enterprises or organizations share the right to use idle resources through sharing platform and achieve the efficient use of resources. This paper first analyzes the business model of the OFO bicycle-sharing and compares it with the business model of the car-hailing, then summarizes the business model of sharing economy based on the analysis of the innovation of business model in sharing economy. Finally, the dissertation concludes that the sharing economy is seen as an irresistible economic development trend.
\end{abstract}

\section{Discussion on the Business Model of Sharing Economy}

\section{The Case Analysis of Sharing Economy}

Nowadays, the sharing economy continues to develop in depth, and is much sought after by the public and capital. Due to the impact of low-carbon environmental protection concept, bicycle-sharing is one of the most talked about sharing economy. In fact, a long brewing scheme of bicycle-sharing in China began a large-scale outbreak in the second half of 2016 at the best of times. In just a few months, the bicycle-sharing of OFO developed from the original campus bikes to spreading out to 22 cities in China and attracted more businesses to a new era of sharing economy. Recently, bicycle-sharing of OFO can be seen everywhere, whether on the subway or campus. OFO has its unique business model in the field of bicycle-sharing as the world's first non-pile bicycle-sharing creator. OFO creatively promotes a 1-to-N sharing method that allows users to provide their bicycles to the OFO, and the provider will be able to enjoy all OFO bicycle-sharing for free. There is two main channel about bicycle source of OFO, purchase by the company itself and free to share with users. Users can find the nearby idle bicycle-sharing through the mobile phone software, and then users can unlock the shared bikes by sending the license plate number to the OFO online platform. These bicycles are equipped with Global Position System, and can be placed anywhere in public for the next user. They are popular among many citizens as they efficiently solve the "last mile" problem. In this short period, bicycle-sharing has become a typical representative of sharing economy, and the degree of heat exceeded the car-hailing like Uber. If you have some comparison with the business model of the bicycle-sharing and car-hailing, it is not hard to find the bicycle-sharing is only the primary stage of sharing economy and car-hailing is a sign of the future of sharing economy.

Firstly, to a large extent, the bicycle-sharing and car-hailing have a lot of similarities that their development depends on the development and application of Internet technology. What is more, the bicycle-sharing and car-hailing have similar sharing ideas that "do not ask for all, just use". However, they have a fundamental difference in their business model. Bicycle-sharing uses the B2C model that enterprises can directly face to the user, and most of the components are more like a rental depending on the Internet. The car-hailing employs C2C mode that users directly face to the users, and users can be consumers or providers, which fully embodies the co-construction and sharing component of sharing economy. 
The most typical one of the car-hailing enterprise is Uber that is known as the legend of sharing economy. Uber mainly uses the profit model of a combination of online and offline business that some idle vehicle resources are placed into the sharing economy platform for matching both supply and demand, which met the needs of demand side and supply side. The greatest significance of Uber is to seek the most value of the idle vehicle resources.

\section{Business Model of Sharing Economy}

From what has been discussed above, it can be summarized in the general business model of sharing economy. The business model of sharing economy uses the Internet as a platform for the operation, and its fundamental structure is "idle resources + utilization value + corresponding return". The platform itself of sharing economy does not directly own the ownership of the idle resource. The owner of the idle resource is the products and services provider who transfers the right of the resource use to the side who needs them for a certain period. The supplier does not transfer ownership while transferring the right to use, and the ownership is still owned by the supplier. The demand side can only enjoy the goods or services by way of rent or shared. The business model of asset-light operation not only created value for the demand side to solve their urgent needs, but also for the supply side to provide the appropriate return.

\section{An Advantage Analysis of the Business Model of Sharing Economy}

The advantages of the business model of sharing economy are mainly manifested in the following three aspects. First, the business model of sharing economy has a large price advantage compared to the traditional business model. This price advantage is mainly due to its cost advantage that shows up as lower operating costs without the middleman. Second, the business model of sharing economy is a way to have the right to participate both demand side and supply side in the model differing from the traditional business model. The demand side becomes more autonomous in sharing economy, he can feed back their feeling to the supply side and Sharing platform, so that the business model of sharing economy can meet the individual demand and customized services. Third, the business model of sharing economy is conducive to the sustainable development of society. The configuration object of sharing economic business model is idle resources, and these resources can be used repeatedly and efficiently, which makes the enterprise without a lot of resources. To a large extent, it not only reduces the company's operating costs, but also realizes the sustainable utilization of social resources.

\section{The Innovation Performance of Business Model under Sharing Economy}

\section{Innovation of Value Orientation}

If an enterprise wants to succeed in a complex and volatile market, it must first clear the value of the enterprise itself, that is to identify the target consumer groups and how to meet the needs of consumers. The primary factor in the modern business model is to satisfy the needs of consumers, so that the supply and demand can be efficiently matched, which requires modern enterprises to learn quickly locate the market demand. All of those cannot be fully realized for the traditional business that information dissymmetry exists in supply and demand. The business model of sharing economy can be adjusted with this core element. In the sharing economic business model, enterprises are using the Internet sharing platform to achieve rapid interconnection both supply and demand, which help complete the effective sharing of idle resources. The flexibility of the sharing platform itself makes the individual needs of consumers to be met in large part.

\section{Innovation of Transaction Model}

In the traditional business model, the enterprise is focused on the supply chain trading model. This model makes the enterprise to carry out supply chain organization model that is the more heavy asset, which increases the operating costs and risks. In the sharing economic business model, the enterprise taking a more flat trading model are more inclined to the light asset operation that is more flexible and focused on what is best for the enterprise development. Taking Uber as an example, the 
demand for travel is not from the sharing platform itself, but from the passengers. Uber and the owner is not a supply chain Relationship, but is a cooperative or alliance relationship, which is an innovation different from the traditional business model in the relationship between sharing economy and its stakeholders.

\section{Innovation of Core Competence}

Any business cannot develop without its core resources and ability. In the traditional business model, the enterprise's core resource capacity usually refers to the product quality, innovation ability and cost price, etc. In the sharing economic business model, the core resource capacity is the emerging Internet information technology; this is because the sharing economy is based on the Internet information technology and the sharing platform is the only platform to sharing economy.

\section{Innovation of Profit Model}

Profitability refers to the income and cost structure of the enterprise and the source of the profit. In the traditional business model, the profitability of enterprises is relatively simple. Costs mainly contribute to suppliers, internal operations and staff salaries, and the revenue is from consumer spending. In the sharing economic model, because the sharing economy is based on the Internet, its profitability is more diversified. Its income comes not only from the demand side of the sharing economic platform, but also from its suppliers. The main forms of income are the proportion of the commission. The cost of sharing economy is relatively simple, and the enterprise invests quietly a lot cost into information technology upgrading and routine maintenance of sharing economy platform. Therefore, the sharing economic business model can not only try to maximize the value of excess resources, and but also reduce the cost of the enterprise to improve its profitability.

\section{Innovation of the Enterprise Value}

The enterprise that adopts traditional business model takes a heavy asset model, which not only brings a higher operating costs to the enterprise itself, but also reduces the profit margins of the enterprise, and a large number of idle resources cannot be efficient use to hinder the sustainable development of this enterprise. The business model of sharing economy to take light asset model and the traditional model is the opposite, and the former only needs to match idle resources with the effective needs through the Internet platform so as to achieve the transfer of the use right of idle resources. This light asset model of sharing economy has largely reduced the operating costs of the enterprise, expanded the profit margins, and thus achieved the sustainable growth of the enterprise value.

\section{Innovation of Cash Flow Structure}

The cash flow structure refers to the structure and shape of cash inflows and outflows of enterprises, which reflects the financial status of the whole enterprise to a large extent. Because sharing economy employs the Internet information technology as the main support, it belongs to the light asset model that sharing economic enterprises can get more with less, which is not only a great Innovation, but also an important reason for some venture capital companies to support the sharing economic enterprises.

\section{Conclusion}

In summary, the business model of sharing economy has many innovative places, and it has certain advantages over one with the traditional economic model. At present, the development of sharing economy also has some obstacles, including imperfect law, interest groups and other aspects, which needs the government to do the appropriate institutional arrangements. First of all, the government must establish a sharing economic credit system. The credit between the parties is the basis of sharing economy development, and the existence of credit protection contributes to the healthy development of sharing economy. Second, the government should establish a mechanism to protect the interests of the supply side and regulate the supply behavior of the supply side through the 
protection of the demand side, which helps to achieve sustainable development of sharing economy. Finally, the government should focus on strengthening the supervision of the sharing economic platform, and urge the sharing platform to carry out information disclosure, thereby protecting the interests of both supply and demand.

In the future, the sharing economy has been regarded as the mainstream direction of global economic development. "Sharing the economy" is not just a simple trend, and it also indicates that a new economic model is coming. This new business model will not only change people's lives and consumption patterns, and will lead the whole social change. As Amazon has changed the traditional bookstores, Airbnb has been able to change the traditional hotel industry.

\section{Reference}

[1] Zhi-Lai ZHENG, Research on the causes, connotation and business model of sharing economy[J], Modern economic exploration, 2016 (3)

[2] Cheng-Hui DONG, Sharing economy: theory and reality[J],Journal of Guangdong University of Finance and Economics, 2016 (5)

[3] Han-Qing YE, Sharing economy: the rise of a new business model[J], Modern Business, 2016 (22)

[4] Xiao-Dong RUAN, Sharing economic era[J],New Economy Weekly, 2015 (4)

[5] Huai-Yong LI, Gui-Peng ZHANG, The innovation of Business Model Based on Sharing Economy[J],Journal of Commercial Economics, 2017 (1)

[6] Yan YI, the brief introduction of sharing economic development[J], Financial Accounting, 2015 (12)

[7] Hong-Wu QIAO, Jiang-Cheng ZHANG, Sharing economy: a new normal state of economic ethics[J],Tianjin Social Sciences, 2016 (3)

[8] Si CHEN, Meng-Ran LIU and Yue-Huan LIU, Analysis of sharing economic model[J], Modern business,2017 (4)

[9] Hamari, J.,\& Ukkonen, A,The sharing economy: Why people participate in collaborative consumption. Helsinki Institute for Information Technology, 2013

[10] Georgios Zervas, Davide Proserpio, John W. Byers, The Rise of the Sharing Economy: Estimating the Impact of Airbnb on the Hotel Industry[R]. working paper, 2015.

[11] Hai-Yang XU, Xian-Zhao ZHAN, Mode research on sharing economy[J], Co-operative Economy and Science, 2017 (3) 